\title{
Interaction of Mono- and Dinuclear Metal Complexes with Mono- and Oligonucleotides for Analytical, Radio- and Chemotoxic Purposes
}

\author{
Bernhard Spingler, Fabio Zobi, Philipp M. Antoni, Alfredo Medina-Molner, and Roger Alberto*
}

\begin{abstract}
In this article we briefly describe our recent results concerning the interaction of mononuclear $\left[\mathrm{M}(\mathrm{CO})_{3}\right]^{+}$

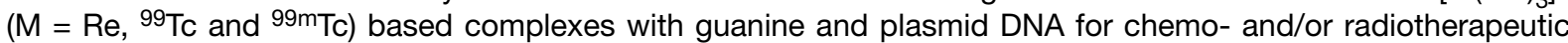
purposes. Furthermore, studies with mono- and dinuclear, coordinatively unsaturated $\mathrm{Ni}(I)$ and $\mathrm{Cu}(I)$ complexes inducing B- to Z-DNA transitions are outlined. The strong interaction of $\left[\mathrm{M}(\mathrm{CO})_{3}\right]^{+}$with one guanine allows the direct introduction of this core into oligodeoxynucleotides (ODN), without their previous derivatization, for further elucidation of their biological behavior. Vectors labeled in this way can later be used in radioimaging or -therapy studies. The $\left[\mathrm{M}(\mathrm{CO})_{3}\right]^{+}$core can also mediate the introduction of further biologically active or, for analytical purposes, fluorescent molecules. Alternatively, ODNs can be derivatized with amino acid based chelators such as histidine. We describe the induction of structural changes in plasmid DNA observed after reaction with the $\left[\mathrm{M}(\mathrm{CO})_{3}\right]^{+}$ moiety. This indicates a cisplatin-like behavior useful for future chemotherapy. Finally, studies of the interaction of mono- and dinuclear complexes with ODN inducing B- to Z-DNA transitions are described and compared to the effect of common electrolytes alone. A clear correlation between salt type and salt concentration was found. These complexes have a strong potential to be used for analytical or biological purposes as well.
\end{abstract}

Keywords: DNA cross-link · Oligonucleotide $\cdot$ Rhenium $\cdot$ Technetium · Z-DNA

\section{Introduction}

The objective of our research is the study of metal-nucleotide interactions for the purpose of applying the corresponding compounds as novel DNA targeting metallodrugs. Within this very broad goal, we focus on the study of basic nucleotide-metal interactions to achieve i) a cisplatin like chemotoxic action or ii) damage DNA by particle irradiation from $\beta^{-}-, \alpha$ - or Auger electron-emitting radionuclides to induce a

\footnotetext{
${ }^{*}$ Correspondence: Prof. Dr. R. Alberto Universität Zürich

Anorganisch-chemisches Institut

Winterthurerstr. 190

$\mathrm{CH}-8057$ Zürich

Tel.: +4116354631

Fax: +4116356803

E-Mail: ariel@aci.unizh.ch
}

radiotoxic action and iii) induce a B- to ZDNA transition by means of mono- or dinuclear metal complexes. It would be intriguing to combine points i) and ii) with the same metal complex in order to enhance the therapeutic index. Nowadays, it is accepted that neither radiotherapy nor chemotherapy alone will be the future way of treating diseases such as cancer, instead a decent combination of both procedures at the same time or in sequence will increase the chance for curing cancer substantially [1][2]. Furthermore, since Z-DNA has been implicated as a gene-regulating element, metal complexes might be the tool of choice to analytically elucidate the formation of Z-DNA and at the same time a possibility to interfere with structural DNA changes by inducing these transitions or to block the Z-DNA [3]. The three research directions have, thus, their ultimate goal of using mono- or dinuclear metal complexes for the recognition of DNA structures or for the induction of structural DNA changes in common, although the kind of metal complexes are different.

The motivation in research aimed at studying DNA-metal complex interactions emerges from the agreement that the major biological target of platinum compounds is DNA, with its efficacy being correlated with the ability to covalent bind to nucleotides, thereby producing irreversible 1,2intrastrand adducts [4-6]. Beside platinum compounds, the research has expanded to the ' $[(\text { arene }) \mathrm{Ru}]^{2+}$ ' moiety, $\mathrm{Ru}^{3+}$ complexes with imidazole or indazole type ligands and diverse metallocenes [7][8]. The common feature of the former two is their ability to bind to two nucleotides and forming robust complexes.

We describe some basic studies to add a further complex moiety to this series, namely rhenium or technetium based compounds comprising the ' $\mathrm{fac}-\left[\mathrm{M}(\mathrm{CO})_{3}\right]^{+}$' moiety. We explored whether this class is also able to bind to nucleotides and nucleic acids and to induce structural changes in DNA as observed for cisplatin. Since rhenium in particular has radionuclides suitable for radiotherapy, this would ultimately allow the combination of radioand chemotherapy with identical complexes (Scheme 1).

In order to achieve such an action, many chemical and biological barriers have to be 


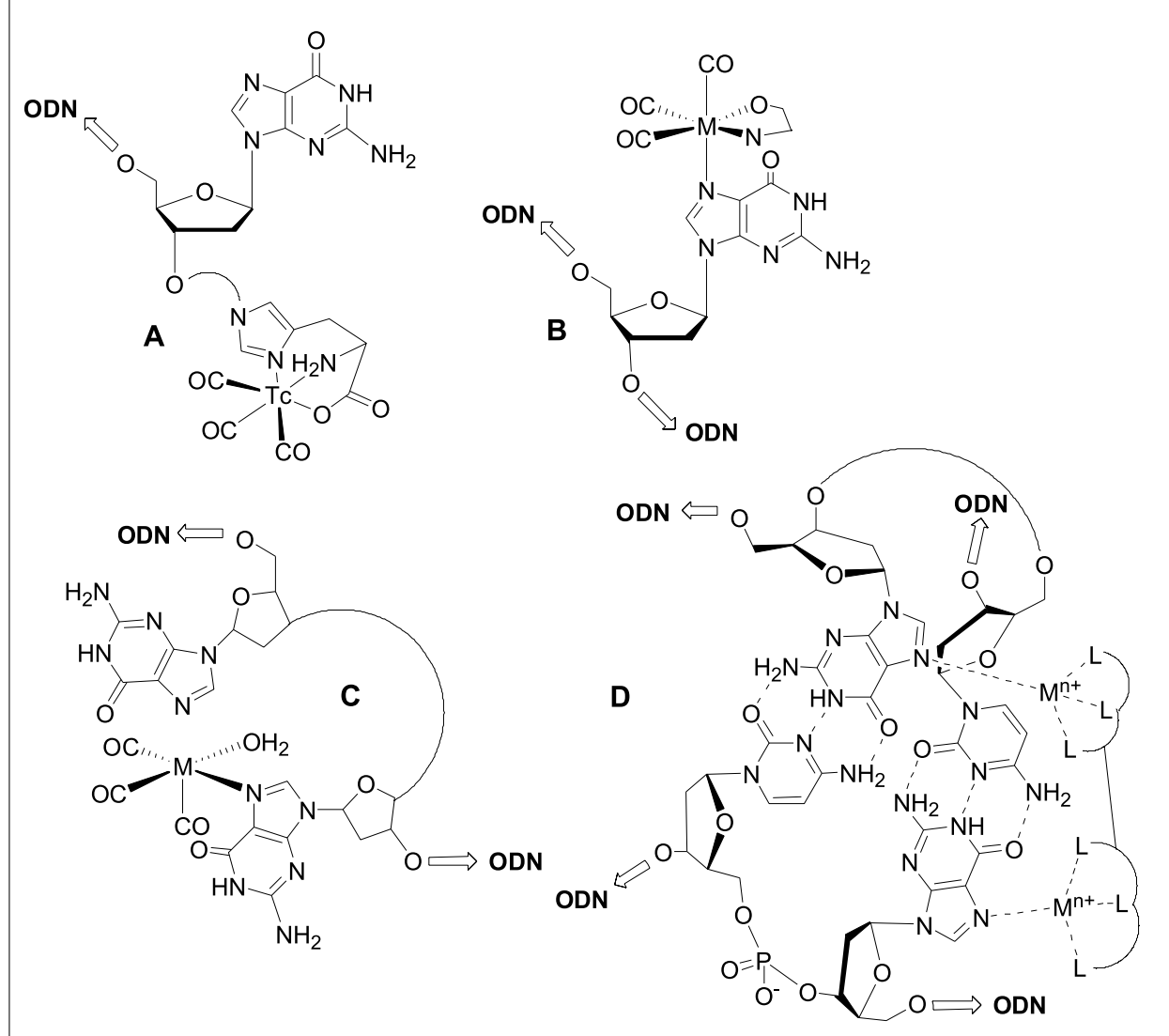

Scheme 1. Modification of oligodeoxynucleotides (ODN) with metal complexes: Introduction of a terminal chelator (histidine) for indirect labeling (A); Direct binding of guanine to rhenium or technetium with or without auxiliary NO ligands (B); Structural changes in oligonucleotides through binding to two adjacent nucleobases (C); Proposed binding of dimetallic complexes to the $N(7)$ positions of two interstrand 1,2-neighboured $\mathrm{G}$ bases in Z-DNA at a $\mathrm{d}(\mathrm{GC})_{\mathrm{n}}$ sequence (D).

overcome. First a suitable complex should be stable in serum and not interact with e.g. serum proteins. Secondly it has to internalize into the cell, preferentially with specificity for cancer cells and finally to find its way into the nucleus whilst or before becoming an active drug. To tailor such a compound is challenging and numerous basic studies are required to design rationally a complex matching all these requirements. This is true not only for the mono- but also for the dinuclear complexes presented here, and in depth knowledge of all single steps is a crucial prerequisite.

Beside a direct interaction of a stable but reactive metal complex with oligonucleotides, modification with a ligand providing high stability to the corresponding metal fragment represents a common strategy of labeling. Introducing a radionuclide such as ${ }^{99 \mathrm{~m}} \mathrm{Tc}$ in these chelators allows then the labeling of the corresponding sequence and, thus, to follow its track and metabolic fate in biological systems. In this case, the metal is 'inactive' and solely a marker or possibly a radiotherapeutic agent. This strategy is mainly applied nowadays in antisense strategy as related to radiopharmacy and has a large potential in cancer diagnostics or therapy [9-11]. Modification of oligonucleotides with a chelator is often (right)

\section{The fac- $\left[\mathrm{M}(\mathrm{CO})_{3}\right]^{+}$Moiety $(\mathrm{M}=\mathrm{Re}, \mathrm{Tc})$ and Guanine}

For the purpose of direct labeling and for exploiting the potential of chemo(radio)toxicity, basic interaction studies of $\left[\mathrm{M}\left(\mathrm{OH}_{2}\right)_{3}(\mathrm{CO})_{3}\right]^{+}$(the $\mathrm{fac}$ $\left[\mathrm{M}(\mathrm{CO})_{3}\right]^{+}$moiety) with nucleobases and oligonucleotides have been performed. To forestall an important result, the fac$\left[\mathrm{M}(\mathrm{CO})_{3}\right]^{+}$moiety has no direct affinity at all to cytidine or thymidine, a very weak affinity for adenine but a very good affinity for guanine. This stands in contrast to other complex fragments, and the differences in affinity are here more distinct than observed for $e$.g. cisplatin. Although it has sometimes been doubted that octahedral complexes can easily adopt two bulky bases in their coordination sphere, no difficulties have been encountered in coordinating two 9-MeG or 7-MeG to the $\mathrm{Re}(\mathrm{I})$ center and the formation of $\left[\mathrm{Re}\left(\mathrm{OH}_{2}\right)(7 / 9-\mathrm{MeG})_{2}(\mathrm{CO})_{3}\right]^{+}$ proceeds to completion within a short time. An X-ray structure of both complexes is shown in Fig. 1 [12][13].

The reaction can well be monitored with HPLC or ${ }^{1} \mathrm{H}$ NMR spectroscopy and kinetic and thermodynamic data can be extracted from the corresponding measurements. These data are essential for a principal comparison to e.g. cisplatin. The reactions with the corresponding numbers are given in Scheme 2, the numbers for cisplatin are in brackets.

Obviously, the rate of formation of $\left[\operatorname{Re}\left(\mathrm{OH}_{2}\right)_{2}(9-\mathrm{MeG})(\mathrm{CO})_{3}\right]^{+}$and $\left[\operatorname{Re}\left(\mathrm{OH}_{2}\right)\right.$ $\left.(9-\mathrm{MeG})_{2}(\mathrm{CO})_{3}\right]^{+}$are comparable to those of cisplatin. The comparison of the different stability constants is difficult since the coordination of a second 9-MeG to $\mathrm{Pt}$ (II) can be considered as irreversible. The thermodynamic and kinetic date imply however, that a strong interaction and a reasonably robust complex with two 9-MeG exists, which is the crucial basis for a direct labeling of Gs in oligonucleotides and/or for exhibiting chemotoxic properties in these complexes.

An interesting feature of the two structures depicted in Fig. 1 is the head to tail

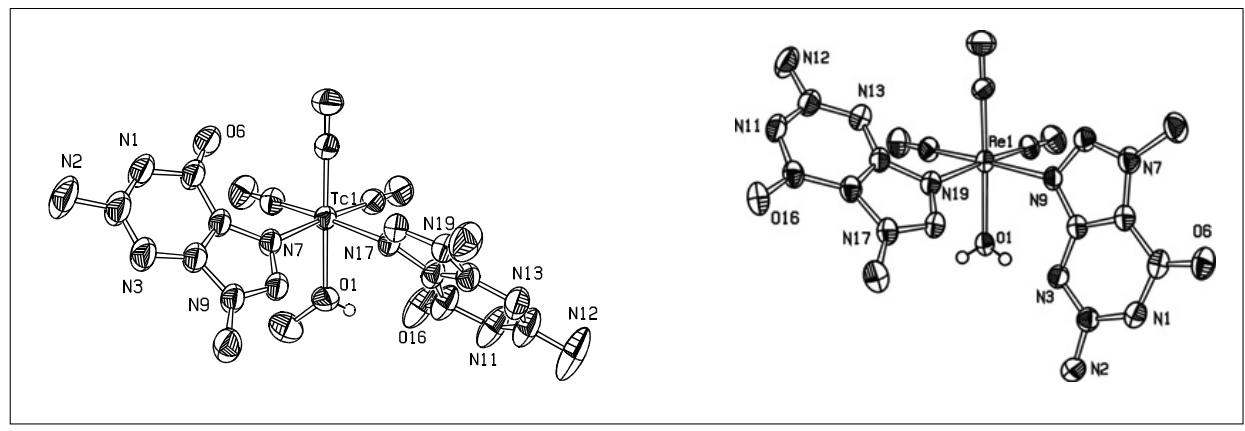

Fig. 1. ORTEP representations of $\left[{ }^{99} \mathrm{Tc}\left(\mathrm{HOCH}_{3}\right)(9-\mathrm{MeG})_{2}(\mathrm{CO})_{3}\right]^{+}(\mathrm{left})$ and $\left[\mathrm{Re}\left(\mathrm{OH}_{2}\right)(7-\mathrm{MeG})_{2}(\mathrm{CO})_{3}\right]^{+}$ 


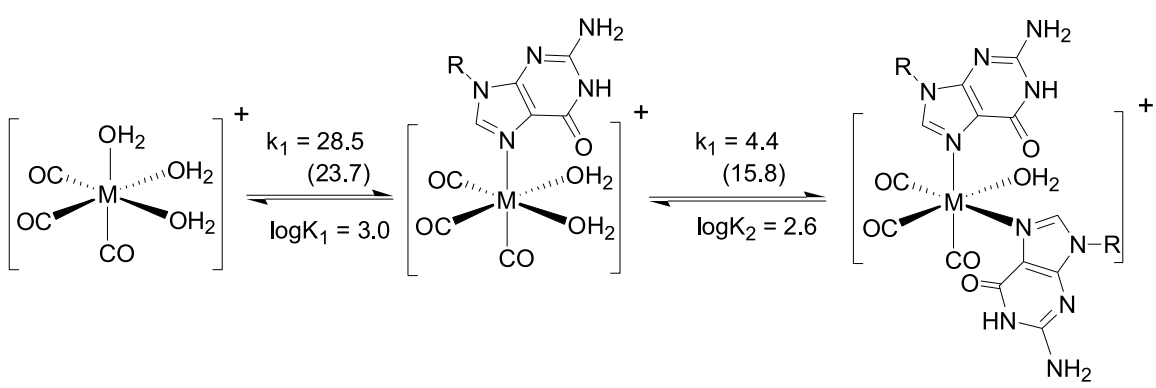

Scheme 2. Rate $\left[\mathrm{M}^{-1} \cdot \mathrm{s}^{-1}\left(\cdot 10^{-2}\right)\right]$ and stability constants for the reaction of $\left[\operatorname{Re}\left(\mathrm{OH}_{2}\right)_{3}(\mathrm{CO})_{3}\right]^{+}$with 9 $\mathrm{MeG}$ in $\mathrm{H}_{2} \mathrm{O}$. The values for $\left[\mathrm{Pt}\left(\mathrm{OH}_{2}\right)_{2}\left(\mathrm{NH}_{3}\right)_{2}\right]^{2+}$ are given in brackets.

(HT) orientation of the two bases. It has been hypothesized that $\mathrm{Pt}(\mathrm{II})$ bound to $\mathrm{dG}$ pG in a HT orientation is easier to repair than in a $\mathrm{HH}$ orientation. Consequently, the HT orientation as found in $\left[\mathrm{Re}\left(\mathrm{OH}_{2}\right)(9\right.$ $\left.\mathrm{MeG})_{2}(\mathrm{CO})_{3}\right]^{+}$would be a disadvantage [14][15]. Different crystallization conditions gave the same complexes in a $\mathrm{HH}$ orientation and DFT calculation showed that the relative energy differences are so small that the isomers are in rapid equilibrium, hence, unhindered rotation of the nucleobases is possible. These theoretical findings are confirmed by NMR studies in which spectra show the same chemical shifts for the $\mathrm{H}-8$ resonances for both complexes even at low temperature [13].

These fundamental results imply that compounds based on the ' $f a c-\left[\operatorname{Re}(\mathrm{CO})_{3}\right]$ ' moiety have the potential of interfering on a molecular level with DNA in a cisplatin-like mode, thus, the important physico-chemical authenticities for the application purposes as outlined in the introduction are given. It has been qualitatively shown that dinuclear $\left[\operatorname{Re}(\mathrm{CO})_{3}\right]^{+}$complexes exhibit in vitro cytotoxic activity [16-18]. In these examples however, the metal core has been 'protected' by very strong ligands which make a direct DNA-Re interaction unlikely. The most reactive complex $\left[\mathrm{Re}\left(\mathrm{OH}_{2}\right)_{3}(\mathrm{CO})_{3}\right]^{+}$showed cytotoxic effects on different cancer cell lines but at a relatively high concentration of 200 $\mu \mathrm{M}$. Since $\left[\mathrm{Re}\left(\mathrm{OH}_{2}\right)_{3}(\mathrm{CO})_{3}\right]^{+}$binds well to proteins in the extracellular media, the actual availability might be much lower and the activity, thus, substantially higher. To extend the basic investigations with the pure nucleobases, we have therefore studied the interaction with plasmid DNA (pDNA) in order to detect binding and eventual structural changes induced in supercoiled and relaxed pDNA.

\section{The fac- $\left[\mathrm{M}(\mathrm{CO})_{3}\right]^{+}$Moiety ( $M=R e, T c)$ and pDNA}

The reactivity of $\left[\mathrm{Re}\left(\mathrm{OH}_{2}\right)_{3}(\mathrm{CO})_{3}\right]^{+}$ (and its Tc surrogate) with guanine and guanosine is the basis for a corresponding interaction with oligonucleotides. Binding to two adjacent Gs should result in conformational structural changes to be detected e.g. by shifts in electrophoretic mobility, a well-established technique. Unwinding of supercoiled pDNA by metal binding causes relaxation, the forces between DNA and the gel matrix will increase and the mobility becomes reduced. Binding to open chain DNA causes the opposite, the conformation becomes more compact and the band will move faster. Different $\mathrm{Ru}$ and $\mathrm{Pt}$ complexes have been analyzed in this way [19-22]. Correspondingly, sc and oc forms of pDNA have been exposed to various concentrations of $\left[\mathrm{Re}\left(\mathrm{OH}_{2}\right)_{3}(\mathrm{CO})_{3}\right]^{+}$and the structural changes detected by mobility shift assays. A typical example of a gel is given in Fig. 2.

As can be seen from the traces, increasing concentrations of $\left[\mathrm{Re}\left(\mathrm{OH}_{2}\right)_{3}(\mathrm{CO})_{3}\right]^{+}$ relative to $\mathrm{pDNA}$ causes a steady conformational change. At ratios of Re/bp of 0.00018 to 0.018 almost no change is visible but at higher ratios conformational changes are induced and the bands shift towards each other. Exposing the same sample of pDNA to cisplatin causes the same changes although already at a 10 times lower concentration. Despite these similarities, the parallels between cisplatin and $\left[\mathrm{Re}\left(\mathrm{OH}_{2}\right)_{3}(\mathrm{CO})_{3}\right]^{+}$are not a direct proof for covalent base binding and could simply be a consequence of electrostatic interaction. Such an argument cannot be readily excluded and only structural analysis in solution or in the solid state would be conclusive in that respect. To support our hypothesis we exposed pDNA to a fully 'shielded' complex in which all coordination sites are occupied with strong ligands such as imidazole or histidine. However, experiments with mono-cationic $\left[\operatorname{Re}(\mathrm{im})_{3}(\mathrm{CO})_{3}\right]^{+}$or neutral $\left[\operatorname{Re}(\mathrm{his})(\mathrm{CO})_{3}\right]$ did not induce any change even at very high Re/bp ratio (Fig. 3). Thus, although not structurally proven, the electrophoretic results imply a strong covalent interaction between pDNA and $\left[\operatorname{Re}\left(\mathrm{OH}_{2}\right)_{3}(\mathrm{CO})_{3}\right]^{+}$. Similar features are also observed for the analogous chemistry with the corresponding ${ }^{99} \mathrm{Tc}$ complexes [23].

\section{Protecting the $\mathrm{fac}-\left[\mathrm{M}(\mathrm{CO})_{3}\right]^{+}$ Moiety with Amino Acids}

Based on the previous basic behavior of $\left[\mathrm{Re}\left(\mathrm{OH}_{2}\right)_{3}(\mathrm{CO})_{3}\right]^{+}$towards nucleobases and pDNA, a chemotoxic, and in the case of substituting 'cold' rhenium with hot ${ }^{188 / 186} \mathrm{Re}$ or ${ }^{99 \mathrm{~m}} \mathrm{Tc}$, a radiotoxic effect could be expected. As mentioned earlier, $\left[\mathrm{Re}\left(\mathrm{OH}_{2}\right)_{3}(\mathrm{CO})_{3}\right]^{+}$binds in serum

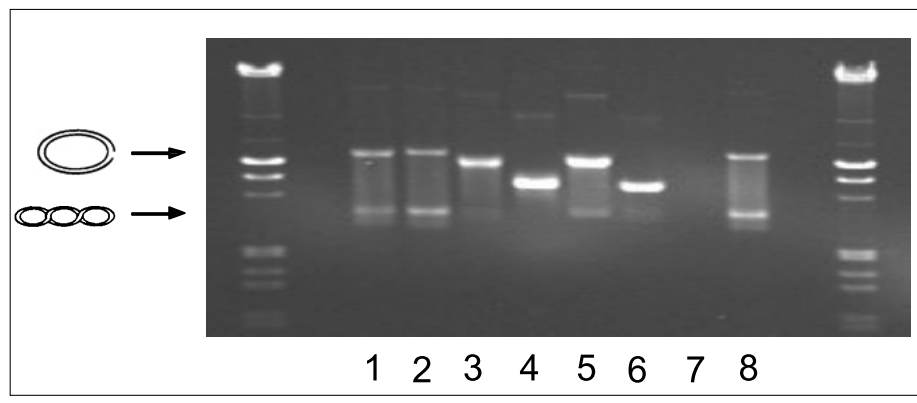

Fig. 2. Electrophoresis in $0.75 \%$ agarose gel of $5 \mathrm{nM} \Phi \times 174$ DNA incubated with various concentrations of $\left[\mathrm{Re}\left(\mathrm{OH}_{2}\right)_{3}(\mathrm{CO})_{3}\right]^{+}$(lanes 2-4) and cisplatin (lanes 5-7). Lanes 1 and 8 reference $\Phi \times 174$ DNA. $r_{b}$ levels for lanes 2-7: $(2,5) 0.018 ;(3,6) 0.18 ;(4,7) 1.8$.

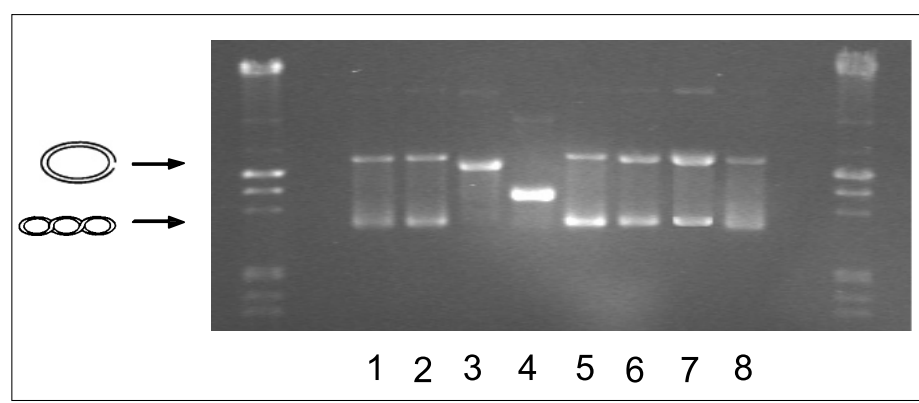

Fig. 3. Electrophoresis in $0.75 \%$ agarose gel of $5 \mathrm{nM}$ ФX174 DNA incubated with various concentrations of $\left[\mathrm{Re}\left(\mathrm{OH}_{2}\right)_{3}(\mathrm{CO})_{3}\right]^{+}$(lanes 2-4) and $\left[\operatorname{Re}(\mathrm{im})_{3}(\mathrm{CO})_{3}\right]^{+}($lanes $5-7)$. Lanes 1 and 8 reference $\Phi \times 174$ DNA. $r_{b}$ levels for lanes 2-7: $(2,5) 0.018 ;(3,6) 0.18 ;(4,7) 1.8$. 
relatively efficiently to competing donors from proteins and is therefore not readily 'bioavailable'. It has been shown in animal experiments that $\left[{ }^{99 \mathrm{~m}} \mathrm{Tc}\left(\mathrm{OH}_{2}\right)_{3}(\mathrm{CO})_{3}\right]^{+}$has a long residence time in the blood pool and is not rapidly excreted, a conclusive observation for the bioavailability of the compound. Therefore potential chemo/radiotoxic activity of these compounds is low. In addition, the compounds are unspecific since no specific receptor binding vectors are attached. In an effort to bypass the first disadvantage, exchangeable sites on $\operatorname{Re}(\mathrm{I})$ have to be protected with ligands potentially substituted by bases from nucleic acids, preferentially guanine. Such ligands should on the other side not be readily displaced by e.g. thioether or imidazole from methionine and the histidine side chains respectively. Amino acids are likely to fulfill these requirements. Primary amines and carboxylate groups as bidentate chelators are not too strongly binding to $\operatorname{Re}(\mathrm{I})$ and exhibit a certain lability. Ideally, these protecting groups will form a $\operatorname{Re}(\mathrm{I})$-prodrug being displaced exclusively by guanines.

A number of amino acid complexes comprising the $\left[\operatorname{Re}(\mathrm{CO})_{3}\right]^{+}$moiety have been prepared and the structure of the proline complex $\left[\operatorname{Re}(\text { pro })(\mathrm{CO})_{3}\right]_{3}$ is shown in Fig. 4.

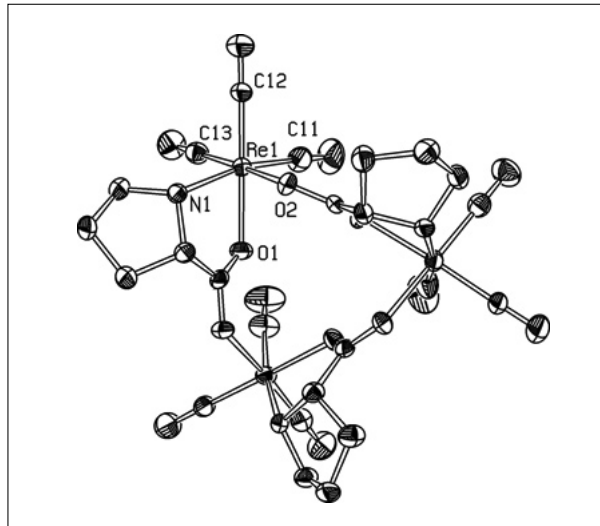

Fig. 4. ORTEP presentation of the prodrug-like complex $\left[\operatorname{Re}(\text { pro })(\mathrm{CO})_{3}\right]_{3}$

In the solid state, the complex forms a trinuclear structure with the carboxylato group of the amino acid binding to two subunits by one oxygen each. Similar structural features have also been observed with $\left[\left(\eta^{\mathrm{n}}-\right.\right.$ arene) $\mathrm{M}(\mathrm{L})_{3}$ ] with $\mathrm{M}=\mathrm{Ru}, \mathrm{Os}, \mathrm{Rh}$ and $\mathrm{L}$ $=$ amino acid [24]. In aqueous solution, the trinuclear structure is probably cleaved and mononuclear species of the composition $\left[\mathrm{Re}\left(\mathrm{OH}_{2}\right)(\mathrm{pro})(\mathrm{CO})_{3}\right]$ are formed. These complexes are stable but the proline is not replaced in the presence of guanine. The only interaction which is observed is replacement of the coordinated $\mathrm{H}_{2} \mathrm{O}$ ligand by one $9-\mathrm{MeG}$ and the formation of $[\operatorname{Re}(9-$
$\mathrm{MeG})($ pro $\left.)(\mathrm{CO})_{3}\right]$. The bidentate proline is too strongly bound and cannot be replaced by the monodentate nucleobases. If the ${ }^{99} \mathrm{Tc}$ analogue $\left[{ }^{99} \mathrm{Tc}\left(\mathrm{OH}_{2}\right)(\mathrm{pro})(\mathrm{CO})_{3}\right]$ is reacted with pDNA, a slow but steady decrease of the free complex was observed, indicating that binding to pDNA took place as in the case of rhenium but through one single guanine in the oligonucleotide only. Although not useful for the purpose of inducing structural changes, direct labeling of oligonucleotides through such a $[2+1]$ approach is possible [25]. A comparable behavior was also found for other amino acids such as glycine or alanine. To decrease the affinity, N,N-dimethyl-glycine (dmg) was chosen based on the knowledge that alkylated amines are weaker ligands. Trinuclear complexes were also formed and the structures confirmed by X-ray structure analysis. The decreased stability now resulted in the substitution of dmg by guanine. Upon exposition of the complex to $9-\mathrm{MeG}$ or 7 MeG, HPLC analysis and ESI-MS revealed a stepwise substitution of coordinated $\mathrm{H}_{2} \mathrm{O}$ and dmg. The aforementioned product $\left[\mathrm{Re}\left(\mathrm{OH}_{2}\right)(9-\mathrm{MeG})_{2}(\mathrm{CO})_{3}\right] \quad$ (see Fig. 1) formed in equilibrium with its mono-coordinated species $\left[\mathrm{Re}\left(\mathrm{OH}_{2}\right)_{2}(9-\mathrm{MeG})(\mathrm{CO})_{3}\right]$. A reaction scheme and an HPLC trace is depicted in Fig. 5. Before proceeding to the reactivity with pDNA it is worthwhile to note at this point that all the complexes with amino acids are stable towards serum protein challenge. An expected slow exchange of coordinated $\mathrm{H}_{2} \mathrm{O}$ for a competing group in the side chains of the amino acids was found but occurred, if at all, only very slowly. Model reaction with the amino acid complexes and simple amino acids such as met or even his confirmed this process but much less rapid than the reactions with 9 MeG.

As expected, the reaction of $\left[\operatorname{Re}(\mathrm{dmg})(\mathrm{CO})_{3}\right]_{3}$ with pDNA shows now the same conformational changes as with the original compound $\left[\mathrm{Re}\left(\mathrm{OH}_{2}\right)_{3}(\mathrm{CO})_{3}\right]^{+}$ This experimental finding implies release of the protecting group from the $\operatorname{Re}(\mathrm{I})$ center and binding of two Gs probably in a cisplatin-like way. Challenging these adducts with large amounts of histidine, knowingly a very strong ligand for the $\left[\mathrm{M}(\mathrm{CO})_{3}\right]^{+}$moiety, does not reverse the structural changes emphasizing strong (or robust) binding to pDNA.

The dmg-protected $\left[\operatorname{Re}(\mathrm{CO})_{3}\right]^{+}$complex is at least in vitro an excellent prodrug. It reacts preferentially with aromatic amines thereby cleaving the protecting group and releasing the active part of the potential metallo-drug. The dmg ligand is very simple and can be attached to $e . g$. a biological vector with or without a cleavable linker and following pathway $\mathrm{A}$ and $\mathrm{C}$ respectively as outlined in Scheme 1. Although the experimental verification of modifica- tion of oligonucleotides with metal complexes is essentially based on rhenium, we emphasize that the same experiments can be performed with long-lived ${ }^{99} \mathrm{Tc}$ or with the short-lived medicinally useful radionuclide ${ }^{99 \mathrm{~m}} \mathrm{Tc}$. The ultimate objective of this research as mentioned in the beginning, combining radio- and chemotoxicity with principally equal compounds, has not yet been reached but some of the major steps are understood and allow further rational metallo-drug finding on a molecular level.

Beside the interaction of mononuclear rhenium and technetium complexes we are also interested in the interaction of dinuclear complexes with oligonucleotides and DNA and the induction of conformational structural changes. These investigations have principally similar objectives but the nature of the complexes and the intended B- to Z-DNA transitions require different analytical tools.

\section{Mono- and Dinuclear Complexes Inducing Z-DNA}

Amongst the different conformations that double-stranded DNA can adopt, the most common is the right-handed B-DNA. However, purine-pyrimidine alternating polynucleotide sequences can adopt a lefthanded helix [26]. In this so-called Z-form, the nucleotides alternate between the standard anti conformation and the more compact syn conformation with the base essentially sitting on top of the deoxyribose ring (see Scheme 1D). In vivo, Z-DNA is stabilized by the negative supercoiling generated by a transcribing RNA polymerase. Z-DNA has been shown to act as an additional gene regulating element [27]. Since the occurrence of Z-DNA has been linked with transcription, one can postulate that the level of Z-DNA correlates with the enhanced transcription rates in fast proliferating cancer cells. The protein dsRNA adenosine deaminase (ADAR1) binds to Z-DNA with nanomolar affinity [28]. The $\mathrm{X}$-ray and NMR structure of a Z $\alpha$ domain of the human editing enzyme ADAR1, binding to a sixmer of Z-DNA, showed that the protein mainly interacts with the negatively charged phosphate backbone of the Z-DNA [29][30]. So far, four proteins have been found which all contain Z-DNA binding domains [31].

Most in vitro studies of the formation of Z-DNA are done in aqueous solutions with extremely high salt concentrations (e.g. $>2.5 \mathrm{M} \mathrm{NaCl}$ ). However, Z-DNA can also be induced by transition metals such as nickel salts or complexes [32]. Such systems allow a more subtle study of the formation of Z-DNA, since they are efficient at approx. stoichiometric concentrations. 


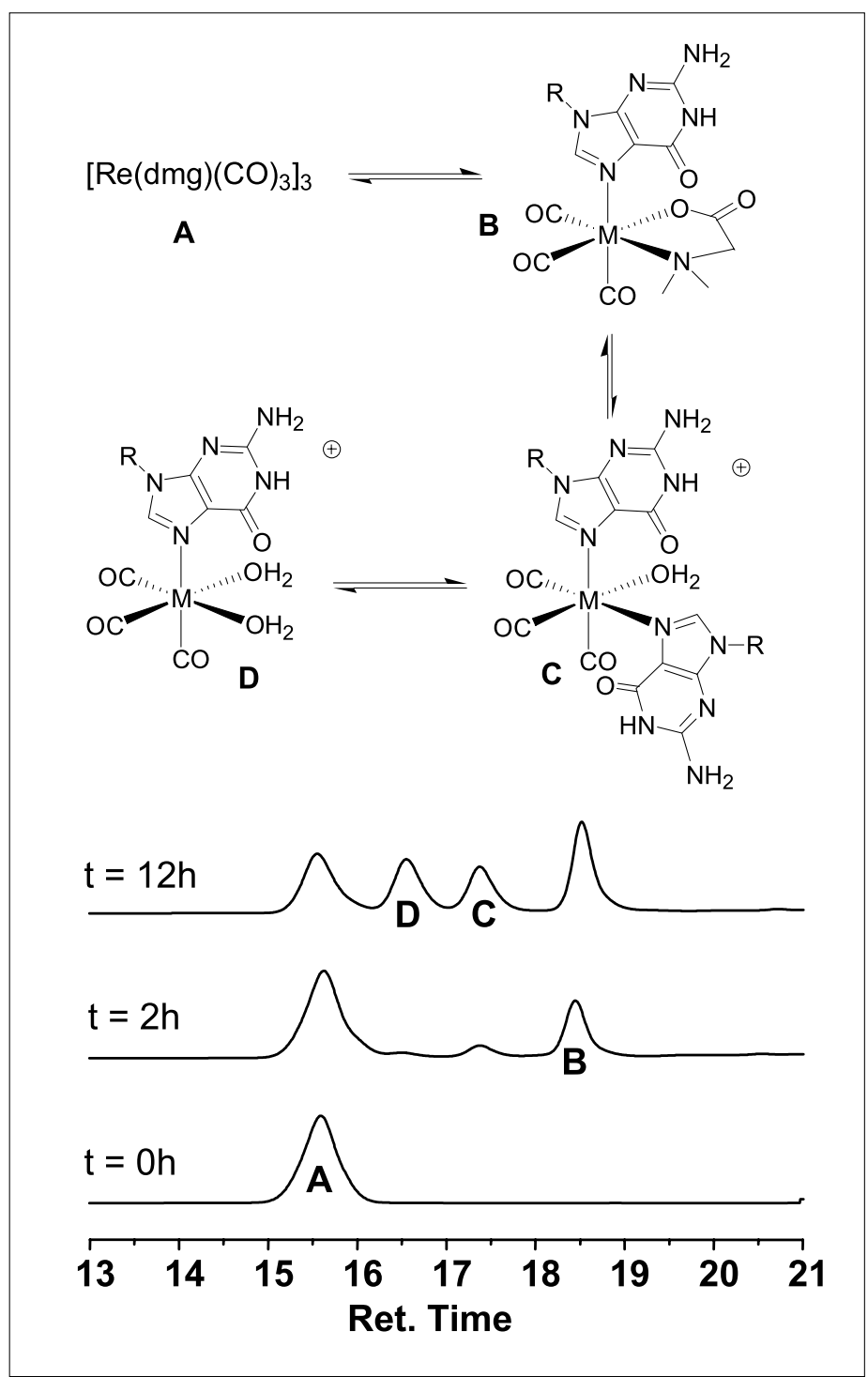

Fig. 5. Stepwise substitution of $\mathrm{dmg}$ in $\left[\operatorname{Re}(\mathrm{dmg})(\mathrm{CO})_{3}\right]$ by $9-\mathrm{MeG}$

We started a research project in order to:

- study the transition of B- to Z-DNA in more detail;

- design, synthesize and test new dinuclear metal complexes for their improved ability to induce Z-DNA compared with the mononuclear analogues;

- derivatize these improved Z-DNA binding units with either fluorescent markers to use them as molecular beacons for the formation of Z-DNA or DNA damaging moieties in order to make use of the increased occurrence of Z-DNA in fast-proliferating cells for chemotoxic treatment.

For a long time, it has been known that the induction of Z-DNA by aquo ions of transition metals is inhibited by even low concentrations (around $10 \mathrm{mM}$ ) of sodium chloride [33]. This is remarkable because sodium chloride on its own, but at much higher, molar concentrations converts suitable DNA sequences to the Z-form. We explored this phenomena by titrating nickel
Salt

$\mathrm{NaCl}$

$\mathrm{Me}_{4} \mathrm{NCl}$

$\mathrm{LiCl}$

$\mathrm{MgCl}_{2}$

no salt

$\mathrm{NaBF}_{4}$

$\mathrm{NaNO}_{3}$

$\mathrm{NaClO}_{4}$ nitrate to poly d(GC) in various aqueous solutions containing $10 \mathrm{mM}$ of either sodium or chloride-containing salts and recording the circular dichroism (CD) spectra [34]. The midpoints of the nickel induced $\mathrm{B}$ - to
Z-DNA transition show a clear dependency of the type of salt present (Table) which do not correlate with the transitions induced by the salt itself. Instead all salts that contain chloride anions inhibit the Z-DNA induction by nickel. The reason for this behavior remains unclear, since the binding constant of chloride to nickel is very low: The logarithmic binding constant $\log \beta_{1}$ of $\mathrm{Ni}^{2+}$ and $\mathrm{Cl}^{-}$to form $[\mathrm{NiCl}]^{+}$is -0.8 [35]. This means that in a $10 \mathrm{mM} \mathrm{NaCl}$ solution with a $\mathrm{Ni}^{2+}$ concentration of $0.1 \mathrm{mM}$, only $0.2 \%$ of all the nickel ions were present in the form of a mono cationic complex $[\mathrm{NiCl}]^{+}$.

During our studies aimed at a better understanding of the factors which influence the formation of the left-handed Z-DNA, we speculated that dinuclear metal complexes might induce Z-DNA more efficiently than their mononuclear analogues [36]. In ZDNA the $\mathrm{N}(7)$ of guanine is especially exposed to the solvent. Metal ions coordinate selectively to this position when Z-DNA crystals are soaked in solutions that contain inorganic cations. As a consequence, sterically demanding metal complexes might be able to preferentially bind to Z- rather than to B-DNA. This would be a new way for a selective recognition of Z-DNA based on homometallic dinuclear complexes (see Scheme 1D). The ideal complex should have the following characteristics:

- metal to metal distance between $5 \AA$ and $7 \AA$;

- binucleating ligand with two sterically not too demanding chelating moieties;

- flexible bridging unit which permits optimal coordination to the DNA bases;

- each metal cation having at least one labile coordination site left.

Based on these restraints, we searched the Cambridge Structure Database and selected several lead compounds [37]. The formation of Z-DNA will again be followed by circular dichroism (CD) as exemplified in Fig. 6 from the work on mononuclear complexes [36].

Table. Nickel-induced B- to Z-DNA transition at $10 \mathrm{mM}$ salt concentrations ( $5 \mathrm{mM}$ for $\left.\mathrm{MgCl}_{2}\right)$ compared with salt promoted B- to Z-DNA transition of poly d(GC). Taken from [34].
Equiv. of $\mathrm{Ni}^{2+}$ needed for the midpoint of the $\mathrm{B}$ - to Z-DNA transition

1.75

1.75

1.7

0.7

0.55

0.2

0.2

0.15
Midpoint of B- to Z-DNA induced by the salt alone
$2.4 \mathrm{M}$

$3.2 \mathrm{M}$

$>5 \mathrm{M}$ at $67^{\circ} \mathrm{C}$

$0.7 \mathrm{M}$

no transition

unknown

lower than $2.4 \mathrm{M}$ 
a)

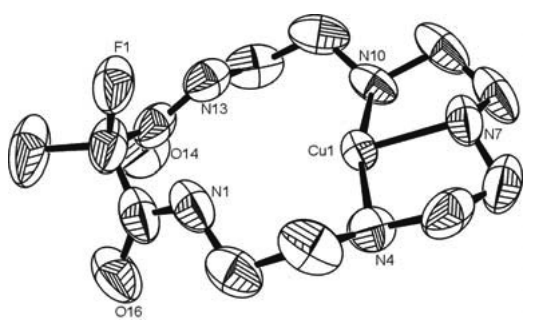

b)

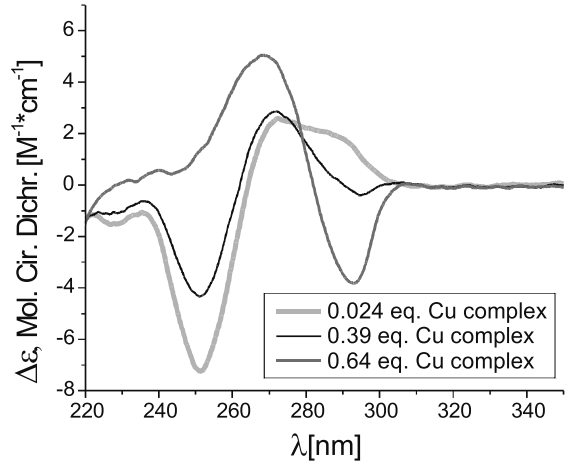

Fig. 6. a) Example of a mononuclear Cu complex used in the B- to Z-DNA studies; b) circular dichroism spectra of poly $\mathrm{d}(\mathrm{GC})$ after adding $0.024,0.39$ and 0.64 equivalents of the copper complex [36]

\section{Conclusion and Perspectives}

The search for metal complexes directly interacting with oligodeoxynucleotides for labeling or for inducing reversible as well as irreversible conformational changes for medicinal or analytical purposes is a challenging multi-component task. Despite enormous research efforts worldwide, no new principally metallo-drugs have really replaced or complemented cisplatin in its role as a leading anticancer drug so far. Future promising candidates have been explored and are certainly in the 'pipeline' but there is a clear requirement for other metal containing precursors. Although being far away from even preclinical trials, the tricarbonyl complexes show the typical features for a metallo-drug interacting in a cisplatin-like mode with oligonucleotides. We presented here some basic aspects of the less common metal complexes based on the $\left[\mathrm{M}(\mathrm{CO})_{3}\right]^{+}$moiety and first steps in the direction of dinuclear metal complexes. Both allow inherently the combination with weak protecting ligands and coupling to biological vectors. The former characteristic is required to prevent unwanted side reactions e.g. in serum while the latter is demanded for accumulating the drug preferentially at the target site. Both have in common that radionuclides which are amongst the most suitable for internal radiotherapy already exist, thus a combination of radio- and chemotherapy will be potentially possible.

\section{Acknowledgements}

We thank all coworkers who have been involved in the practical realization of the presented work, the Forschungskredit of the University of Zürich, the Swiss National Science Foundation, and Tyco-Mallinckrodt B.V. Petten NL for financial support.

Received: August 25, 2005

[1] R.D. Ennis, J. Clin. Oncol. 2004, 22, 2254.
[2] B. Fischer, S. Benzina, V. Ganansia-Leymarie, J. Denis, J.P. Bergerat, P. Dufour, J. Gueulette, P. Bischoff, Can. J. Physiol. Pharm. 2004, 82, 140.

[3] A. Rich, S. Zhang, Nat. Rev. Genet. 2003 , 4, 566.

[4] E.R. Jamieson, S.J. Lippard, Chem. Rev. 1999, 99, 2467.

[5] A. Gelasco, S.J. Lippard, Biochemistry 1998, 37, 9230 .

[6] H. Sigel, B. Lippert, Pure and Appl. Chem. 1998, 70, 845 .

[7] G. Sava, R. Gagliardi, A. Bergamo, E. Alessio, G. Mestroni, Anticancer Res. 1999, 19, 969 .

[8] G. Sava, K. Clerici, I. Capozzi, M. Cocchietto, R. Gagliardi, E. Alessio, G. Mestroni, A. Perbellini, Anti-Cancer Drugs 1999, $10,129$.

[9] N. Thakur, V.K. Tiwari, H. Thomassin, R.R. Pandey, A. Gondor, T. Grange, R. Ohlsson, C. Kanduri, Mol. Cell. Biol. 2004, 24, 7855.

[10] X.B. Tian, M.R. Aruva, P.S. Rao, W.Y. Qin, P. Read, E.R. Sauter, M.L. Thakur, E. Wickstrom, Therapeutic Oligonucleotides 2003, 1002, 165.

[11] A. Thakur, Electron. J. Biotechnol. 2003, 6,39 .

[12] F. Zobi, B. Spingler, T. Fox, R. Alberto, Inorg. Chem. 2003, 42, 2818.

[13] F. Zobi, O. Blacque, H.W. Schmalle, B. Spingler, R. Alberto, Inorg. Chem. 2004, 43, 2087.

[14] P.M. Pil, S.J. Lippard, Science 1992, 256, 234.

[15] S.T. Sullivan, A. Ciccarese, F.P. Fanizzi, L.G. Marzilli, Inorg. Chem. 2000, 39, 836.

[16] Y.K. Yan, S.E. Cho, K.A. Shaffer, J.E. Rowell, B.J. Barnes, I.H. Hall, Pharmazie 2000, 55, 307.

[17] W.W. Wang, Y.K. Yan, T.S.A. Hor, J.J. Vittal, J.R. Wheaton, I.H. Hall, Polyhedron 2002, 21, 1991.

[18] J.Y. Zhang, J.J. Vittal, W. Henderson, J.R Wheaton, I.H. Hall, T.S.A. Hor, Y.K. Yan, J. Organomet. Chem. 2002, 650, 123.
[19] G.L. Cohen, J.A. Ledner, W.R. Bauer H.M. Ushay, C. Caravana, S.J. Lippard, J. Am. Chem. Soc. 1980, 102, 2487.

[20] O. Novakova, H.M. Chen, O. Vrana, A. Rodger, P.J. Sadler, V. Brabec, Biochemistry 2003, 42, 11544.

[21] M. Milkevitch, H. Storrie, E. Brauns, K.J Brewer, B.W. Shirley, Inorg. Chem. 1997, $36,4534$.

[22] M. Milkevitch, E. Brauns, P. Boyer, H. Storrie, B.W. Shirley, K.J. Brewer, Abstr. Pap. Am. Chem. Soc. 1997, 213, 15.

[23] F. Zobi, B. Spingler, R. Alberto, Chem BioChem 2005, 6, 1397.

[24] D. Carmona, M.P. Lamata, L.A. Oro, $J$. Inorg. Chem. 2002, 2239.

[25] S. Mundwiler, M. Kundig, K. Ortner, R. Alberto, Dalton Trans. 2004, 1320.

[26] N. Tang, J.G. Muller, C.J. Burrows, S.E. Rokita, Biochemistry 1999, 38, 16648.

[27] S. Rothenburg, F. Koch-Nolte, F. Haag, Immunol. Rev. 2001, 184, 286.

[28] A. Herbert, A. Rich, J. Biol. Chem. 1996, $271,11595$.

[29] T. Schwartz, M.A. Rould, K. Lowenhaupt, A. Herbert, A. Rich, Science 1999, 284 , 1841.

[30] M. Schade, C.J. Turner, R. Kuhne, P. Schmieder, K. Lowenhaupt, A. Herbert, A. Rich, Proc. Natl. Acad. Sci. USA 1999 , 96, 12465.

[31] S. Rothenburg, N. Deigendesch, K. Dittmar, F. Koch-Nolte, F. Haag, K. Lowenhaupt, A. Rich, Proc. Natl. Acad. Sci. USA 2005, 102, 1602.

[32] H.-C. Shih, N. Tang, C.J. Burrows, S.E. Rokita, J. Am. Chem. Soc. 1998, 120, 3284.

[33] J.H. van de Sande, L.P. McIntosh, T.M. Jovin, EMBO J. 1982, 1, 777.

[34] B. Spingler, Inorg. Chem. 2005, 44, 831.

[35] M. Iuliano, R. Porto, E. Vasca, Ann. Chim. (Rome) 1989, 79, 439.

[36] B. Spingler, C. Da Pieve, Dalton Trans. 2005, 1637.

[37] P.M. Antoni, A. Medina Molner, B. Spingler, unpublished 2005. 